VII International Forum on Teacher Education

\title{
EDITORIAL: TEACHER EDUCATION: NEW CHALLENGES AND GOALS
}

\author{
Ilshat Gafurov \& Tatiana Baklashova
}

\section{Kazan Federal University, Kazan, Russia}

The theme of the VII International Forum on Teacher Education (IFTE 2021) was the ongoing need for researchers worldwide to pursue academic discussions on the transformation of teacher education under the impact of the COVID-19 pandemic. The overall theme of the Forum was "Teacher education: new challenges and goals." There were three parallel conferences held at IFTE 2021: "Teachers for children with special educational needs," "Education trajectories in the time of extremes," and "Training teachers as moral agents in the 21 st century".

The VII International Forum on Teacher Education was held in a mixed format: more than 500 participants visited Kazan and almost a thousand participated in the conference remotely. Over three days over 1,500 Russian and foreign researchers from more than 200 universities worldwide shared their teaching practices. Among them were the leading Russian and foreign researchers in pedagogical education from the universities of Great Britain, the USA, Germany, Canada, Brazil, Finland, Slovenia, Slovakia, Hungary, Romania, Bulgaria, Serbia, Spain, Italy, Poland, India, China, Mongolia, Vietnam, Uzbekistan, Kazakhstan, and many other countries. IFTE 2021 was distinguished by the International Conference for Young Researchers held during the Forum. The Forum's program included 81 sections attended by renowned Russian and foreign experts who discussed the topical issues of education in Russia and the world in the new decade. Simultaneously, 18 research groups and 41 sessions were held. Seventeen prominent international researchers from leading universities in Russia, Great Britain, the USA, Ireland, Australia, and other countries presented their findings.

The Forum was supported by the Russian Academy of Education (RAE), the Russian Education Researchers Association (RERA), and the Federal Academic Methodological Association in the system of higher education on the integrated group of degree programs 44.00.00 "Education and pedagogical sciences". Press Releases about the Forum were published on the websites of Federal and Regional Ministries. The Minister of Science and Higher Education of Russia, the Minister of Education and Science of the Republic of Tatarstan, the President of the Russian Academy of Education, the Presidents of Russian and Kazakh Academies of Education, and the Presidents of International Scientific Associations WERA, ISATT, and IPDA have extended their congratulations.

As the Forum organizers, the researchers of Kazan Federal University have traditionally presented the local practice of developing their own model of pedagogical university education, which has been running since 2011. This model is the result of a large-scale experiment of joining two specialized pedagogical higher education institutions to the traditional multi-profile university. On one hand the model reflects the national traditions and, on the other, introduces modern international trends and best practices to Russian education.

Kazan Federal University has successfully implemented three models of teacher training (traditional, distributed, and integrative) over the past decade. This has improved the attractiveness of the profession of teacher and the variability of educational choices. The diverse global teacher education infrastructure, including 3 schools of various types, additional education centers, a House of Scientific Collaboration for students, a specialized kindergarten for children with autism spectrum disorders, a planetarium, digital labs, video studios, and other facilities have been created. At Kazan Federal University we train professionals for all levels of education, including school, higher and postgraduate education, and ensure their support throughout their career. 
The theoretical and practical potential of the KFU university model was expanded in 2021. This model has been developed within the research-oriented concept of pedagogical education, promoting the best traditions of national pedagogy within the context of the leading international trends. It is noteworthy that, in terms of a large multidisciplinary university, research in pedagogical education is focused on the improvement of the quality of the educational process in other subject areas. Pedagogical innovations have contributed to the progress in higher professional education in medicine, chemistry, physics, biology, mathematics, and humanities.

Kazan Federal University was the first Russian university to be ranked among the world's 100 leading universities in the subject area of "Education" (Times Higher Education Rankings, 2020, 2021). It is currently the only Russian university with a large-scale teacher training program that is represented in the world's leading ratings in the "Education" subject area. Thus, one of the main objectives of Kazan Federal University is to contribute to the promotion of national experience in the international scientific and educational space, as well as to include Russian researchers in the global research community for a fruitful interchange of best practices and expertise in teacher education.

This book presents the proceedings of the three concurrent IFTE 2021 conferences. The proceedings of the first conference cover the issues of teacher training for work in inclusive education systems. The authors focus on approaches, models, and methods that are effective in working with children with special educational needs. Some of the articles are devoted to the study of the application of advanced educational technologies, the introduction of innovations and evaluation of best practices in the education of children with special educational needs, and with ensuring equal educational opportunities for these children, their integration and adaptation in the school environment and society. The proceedings of the second conference cover the issue of teacher education under conditions of extreme circumstances. The researchers focus on the rationale for the essence of education for equity and social justice in a pandemic as well as in conflicts, vulnerability, and uncertainty. A number of articles validate the effectiveness of modern remote learning under extreme conditions and assess the impact of such circumstances on children's learning and well-being. The proceedings of the third conference uncover the teacher-educator training strategies in the modern world. The issues of cultural and professional identity of the modern school teacher are crucial nowadays, and the conceptual and procedural aspect of the teacher-educator training in the 21 st century is highlighted. The researches also address the modern dilemmas of teacher education.

The IFTE 2021 Organizing Committee expresses its sincere gratitude to the members of the Forum scientific committee, represented by leading Russian and foreign scientists in the field of education, and to the editorial board which took the responsibility of ensuring quality and controlling the authenticity of the papers. The Committee also acknowledges the international scientific associations that provided information support to IFTE 2021 and Microsoft for technical support of the Forum.

The main theme of the VIII International Forum on Teacher Education (IFTE 2022) is "Education, Professional Development, and Health Maintenance of Teachers in the 21st Century". The Forum will discuss the current problems of modern teacher education within three Sub-Conferences: "Psychological well-being and teacher effectiveness," "Adapting or changing: the impact of Covid-19 on teacher education," and "Research-based teacher education as a phenomenon of educational anthropology." The Forum will again be held in a mixed format (offline and online) on 25 - 27 May 2022 at Kazan Federal University with the support of Microsoft. We look forward to fruitful cooperation that will be further encouraged by IFTE 2022 and contribute to the mutual enrichment of education systems around the world. 